\title{
Early Childhood Pre-Service Teachers' Conception of Living and Non- Living Things in a Ghanaian College of Education
}

\author{
Sakina Acquah, PhD ${ }^{*}$ \\ University of Education, Winneba, Ghana \\ "Corresponding author: efuaacquah@yahoo.com
}

\begin{abstract}
The study examined pre-service teachers' conception of living and non-living things and their classification using a case study design. The mixed method approach was employed for this study. Census sampling technique was initially used to collect data from 70 participants who complete a questionnaire. Afterwards, purposive sampling technique was used to collect data from 12 of the initially sampled participants using a semi-structured interview guide. The quantitative data were analyzed using descriptive statistics and the qualitative data was analyzed thematically. The findings revealed that $72 \%$ and $93 \%$ of the participants had appropriate scientific conception of living and non-living things respectively, as they were able to correctly classify and justify their classifications of items provided. The findings further revealed that at least $28 \%$ and $7 \%$ of the participants still had intuitive conception of living and non-living things respectively as demonstrated in their inability to classify seven living things and eight non-living things correctly. The educational implication is that Science Educators need to be aware of the intuitive conceptions that pre-service teachers' have about living and non-living things in order to employ appropriate teaching techniques to address the underlying misconceptions during instruction. This will enable pre-service teachers to form sound conceptual understanding of living and non-living things as conventionally known in the scientific community.
\end{abstract}

Key words: Living things, non-living things, conception, intuitive conception, pre-service teachers

\section{Introduction}

In today's world, Science has become pivotal in the developmental aspirations of nations because the level of the quality of life of any group of people is dependent on their capacity to harness scientific knowledge and its application in the form of technology advancements (Gallegos-Ca'zares, Garci'a-Rivera, Flores-Camacho, Caldero' n-Canales, 2016). The obvious disparity between the developed and developing worlds is attributable to scientific and technological advancement. This realization is fueling massive investments into science and technological research so that nations can keep up their competitive advantage over other nations. Developing nations especially are exploring ways of fashioning their educational system to emphasize the learning of Science and Technology in order to develop and make their citizens globally competitive. Towards achieving this aspiration,
Ghana has introduced a new standard-based Science curriculum that has been designed to equip students with the relevant knowledge, skills and attitudes necessary for the development of scientific literacy (National Council for Curriculum and Assessment [NaCCA], 2019). Teachers who are the implementers of the curriculum are also being trained and equipped with the knowledge and pedagogical skills required to effectively implement the curriculum. The curriculum enjoins early grade teachers to use appropriate methods to ground pupils in these topics to enable them acquire the knowledge, skills and values necessary for proficiency in Science. The organization and structuring of this curriculum is designed to ensure that basic and relevant scientific concepts are taught at the early grade/lower primary level because these concepts are seen as pre-requisite for the development of scientific literacy. 
The concept of living and non-living things is a focal topic in the Ghanaian pre-tertiary level Science curriculum. It provides the fundamental knowledge needed for biological studies in later life. At the basic school level in Ghana, biological concepts are included in the Science subjects, with the aim to systematically expose students to the structural functions and behavior of living things In the primary school Science curriculum, living and nonliving things is the first topic to be studied under diversity of matter, which precedes all the other topics such as cycles, systems, forces and energy as well as humans and their environment ( $\mathrm{NaCCA}$, 2019). Since biological sciences focus on living things and their relationship with their environment, a proper conception of living things as distinguishable from non-living things becomes imperative (Gallegos-Ca'zares, Garci'a-Rivera, Flores-Camacho, Caldero' n-Canales, 2016).

For decades, studies have been conducted on the conception of living and non-living things (Duitt, 2007; Opfer \& Siegler, 2004). Piaget (1929) pioneered these studies in in the year 1929. The studies were continued by Laurendeau and Pinard (1962), and later researchers (Babai, Sekal, \& Stavy, 2010; Hatano, Siegler, Richards, Inagaki, Stavy \& Wax, 1993; Özgür, 2018) have also studied how students conceive living and non-living things. In all these studies, what seems to be a simple concept gets difficult due to the intuitive conceptions (misconceptions, alternative or naive conceptions) that students hold about the concept of living and non-living things (Babai et. al., 2010).

This study was illuminated by Vygotsky's (1934/1987) dialectical conceptions of everyday and scientific concepts. According to Davis (2016), Vygotsky conceptualized everyday concepts as intuitive, experienced-based and sporadic. The development of the concepts occurs in out-of-school settings. Scientific concepts, referred to by Gallimore and Tharp (1990) as schooled concepts, on the other hand, are systematic and are acquired through a system of formal instruction. In this study, learners' intuitive conception of living and non-living things i.e. incomprehensive nature is reflected in Vygotsky's everyday concepts due to its sporadic nature. Students still retain their everyday conception/misconception until engaged to transform or modify those concepts to the scientific ones. These intuitive conceptions remain erroneous leading to a wrong classification of things (Babai et. al. 2010; Özgür, 2018).
Conception of living and non-living things depends on a comprehensive understanding of the salient characteristics that designate them as such. The scientific conception of living and non-living things is derived from careful observation and study, leading to a conventional basis of classification. The difference between living and non-living things is based on the biological characteristics exhibited by living things. One of the key characteristics used to distinguish between animate and inanimate objects is autonomous movement (Opfer \& Siegler, 2004; Rakison \& Poulin Dubois, 2001). However, this has been problematic over time due to students' intuitive conception of object mobility (Babai, Sekal, \& Stavy, 2010). Hatano and colleagues (1993), as well as Martinez-Losada, Garcia-Barros and Garrido (2014) reported that some children classified some living things like plants or fungi (e.g., mushroom) as non-living because they lacked autonomous motion. However, non-living objects, often, celestial bodies like the moon, which seem to have motion, are often classified as living (Stavy \& Wax, 1989). Literature suggests that such intuitive conceptions, which are usually prevalent among primary school learners, gradually disappear with age as learners move up the education ladder and are introduced to the appropriate scientific concepts through instruction (Dimec \& Strgar, 2017; Hellden \& Solomon, 2004).

On the other hand, Babai, et al. (2010) argued that such intuitive conceptions persist irrespective of age and academic level. For instance, intuitive mobilitybased conception that all moving objects are living and all non-moving objects are non-living still persists among high school students. The persistence of such intuitive conceptions affects related reasoning processes. This, therefore, suggests that the nature of examples used in explaining the concept of living and non-living things should be those that bridge the gap between intuitive conceptions and actual scientific conceptions (Babai, et al., 2010).

Another justification for students' appropriate conceptions of living and non-living things stems from the concept of diachronic dimension, which they provide. Growth is a characteristic that makes living things distinctive from non-living things. Growth as a result of nutrition leads to death, healing or reproduction among living things. For most learners, it requires a diachronic dimension (that is, the understanding that these biological processes like life cycles occur overtime) to 
understand these processes (Labrell \& Stefaniak, 2011). In between these periods, different conceptions develop concerning what is living or non-living. For instance, Tamir, Gal-Chappin, and Nussnovitz (1981) indicated that participants in their study persistently considered the pupa as dead but the caterpillar alive because they could not observe the diachronic process in the pupa. Again, in Özgur's (2018) study, it came to light that participants classified the human teeth as non-living due to the intuitive conception that the teeth lacked diachronic attributes associated with life processes.

Although not absolute, students' conceptions of living and non-living things differ with age and their opinions to justify their classifications are relevant to how they conceptualize living and non-living things (Noureddinea \& Zouhairea, 2017). Students' conceptions of living things are likened to several functions (Martínez-Losada, García-Barros, \& Garrido, 2014). Bahar (2003) studied students' ideas about life concepts and found that students indicated that all living things have these seven attributes: movement, nutrition, respiration, growth, reproduction, irritability and excretion. However, the findings of Özgür (2018) indicated that the initial conception of living things by children center only on such characteristics as mobility, nutrition, reproduction and respiration. Conversely, the justifications which learners gave for distinguishing items as living or non-living focused primarily on mobility and its presence in nature. Yet the Ghanaian Science curriculum focuses on the identification of living and non-living things on the seven attributes of movement, nutrition, respiration, growth, reproduction, irritability and excretion (NACCA, 2019).

In a qualitative study, Kurt (2013) researched on biology student teachers' cognitive structures of living things by tasking them to give responses in relation to the concept of living things under the seven characteristics used to identify them. Results from this study suggested that participants' conception of living things was superficial and limited. The author further posited that biology student teachers had several intuitive conceptions relating to the concept of living things. He, therefore, recommended that to correct such erroneous conceptions, the difference and similarities between living and non-living things must be explained using examples that are common to learners.
Science educators have conducted several studies on students' conceptions of various scientific concepts (Hanson \& Seheri-Jele, 2018; Fouquet, Megalakaki \& Labrell, 2016; Pringle, 2006), with some focusing on living while others focused on non-living things (Babai et. al., 2010; Kurt, 2013; Özgür, 2018). To a large extent, reviewed studies about conception of living and non-living things have focused on learners in primary and secondary schools. To the best of the researcher's knowledge none of the reviewed studies focused on Early Childhood pre-service teachers' conception of living things and non-living things in the Ghanaian context. In Ghana, living and non-living things are stipulated in the Science curriculum. It is therefore important that prospective teachers' conceptions about living and non-living things is examined since it has implication for their teaching in the future. Therefore, exploring Ghanaian Early Childhood pre-service teachers' conceptions of living or non-living things and the reasons for their classification need to be investigated. This is because the concept runs through from kindergarten to the university level. This study, therefore, sought to answer the following research questions:

1. What conceptions do pre-service teachers have about the classification of living and non-living things?

2. What are the reasons for pre-service teachers' classification of objects as living and non-living things?

\section{Research Methodology}

In line with the pragmatic epistemology, this study adopted the case study design that allows for blending both the qualitative and quantitative approaches in collecting, analyzing and interpreting data in the quest of attaining an in-depth understanding of the case. The rationale for the choice of the case study design was premised on the position that it is an empirical investigation that finds out a contemporary event within its real-life context (Yin, 2009). This is a baseline study that sought to explore first year pre-service teachers' conceptions of living and non-living things; hence it is pertinent that the study was carried in a natural setting of the participants so as to explain the experiences of the participants from their perspectives.

Using the census sampling technique, seventy (70) first year pre-service teachers taking the Bachelor of Education degree in Early Childhood Education, in a Ghanaian College of Education were selected. The 
sample consisted of 23 males and 47 females with ages ranging between 18 to 23 years. Participants' consents were secured in accordance with the researcher's institution's Ethical Committee's policy. The pre-service teachers were undergraduates who had enrolled on a teacher education program upon graduating from high schools.

Data collection was done in two phases. The first phase involved the collection of data using a 20item questionnaire. In the questionnaire, twenty (20) living and non-living things were listed in a random manner and participants were required to indicate which of them were living and which were non-living. Subsequently, 12 of the seventy participants were purposively selected and interviewed. Six out of the 12 participants were selected because they were able to classify all the 20 items as living or non-living. The six remaining participants were selected because they were able to correctly classify $30 \%$ or less of the items as living or non-living. The selection of the participants for interview sessions was made possible because each participant's questionnaire for the quantitative phase was coded prior to its distribution. The semistructured interview protocol/guide required participants to give reasons for classifying each of the twenty items. Each interview session (one-onone type) lasted not more than 30 minutes and was audio recorded with the permission of interviewees. Three Science tutors of the college of education, where the study took place, scrutinized the questionnaire to ensure its face and content validities. The internal consistency of the 20-item questionnaire was acceptable $(\alpha=.71$ Cohen, Manion \& Morrison, 2006). The qualitative data generated from the interview sessions were transcribed verbatim and read over severally in their entirety, reflecting on the interviews as a whole. Then, the researcher summarized the interviews, keeping in mind that more than one theme might exist in a set of interviews. Repeating themes identified were clustered into the reasons why participants classified the items given as either living or non-living things. To ensure trustworthiness of the qualitative data, participants were made to read through their transcripts to ensure it represented their views. Descriptive statistics, percentages and frequencies were used to analyze the quantitative data and the qualitative data were presented using themes that emerged.

\section{Analysis and Findings}

This section begins with analysis of quantitative data and then analysis of qualitative data follows:

\section{Analysis of Quantitative Data}

Analysis of quantitative data focused on responses from the questionnaire regarding pre-service teachers' classification of living and non-Living things. The aim of the study was to explore Ghanaian College of Education Early Childhood preservice teachers' conceptions of living things and non-living things.

Table 1: Frequency Distribution of Participants Responses on Classification of Living Things

\begin{tabular}{lcccccccc}
\hline Items & \multicolumn{3}{c}{ Correct Answer } & \multicolumn{2}{c}{ Incorrect Answer } & \multicolumn{2}{c}{ Undecided } & \multicolumn{2}{c}{ Total Responses } \\
\hline & No. & $\%$ & No. & $\%$ & No. & $\%$ & No. & $\%$ \\
Goat & 70 & 100 & 0 & 0 & 0 & 0 & 70 & 100 \\
Spider & 70 & 100 & 0 & 0 & 0 & 0 & 70 & 100 \\
Apple tree & 70 & 100 & 0 & 0 & 0 & 0 & 70 & 100 \\
Egg & 50 & 71.4 & 13 & 18.6 & 7 & 10 & 70 & 100 \\
Pupa & 45 & 64.3 & 16 & 22.9 & 9 & 12.8 & 70 & 100 \\
Corn seed & 35 & 50 & 15 & 21.4 & 20 & 28.6 & 70 & 100 \\
Grass & 34 & 48.6 & 13 & 18.6 & 23 & 32.8 & 70 & 100 \\
Tomatoes fruit & 31 & 44.3 & 17 & 24.3 & 22 & 31.4 & 70 & 100 \\
Mushroom & 21 & 30 & 19 & 27.1 & 30 & 42.9 & 70 & 100 \\
Human bone & 18 & 25.7 & 44 & 62.8 & 8 & 11.4 & 70 & 100 \\
\hline
\end{tabular}

Participants were asked to indicate whether the list of 20 items were living or non-living. The results on living things are presented separately from that of non-livings in Tables 1 and Table 2 respectively. The findings on participants' classification of living things in table 1 are presented first. Table 1 depicts the number of participants who classified items under the living things category correctly, incorrectly and those who were undecided and as such did not indicate anything with their respective percentage weightings. In Table 1, the items have been listed in the order of magnitude of correct responses from most to least frequent. As seen in Table 1, with respect to the living things items, all the participants 
(70) classified three items; goat (100\%), spider $(100 \%)$, and apple tree $(100 \%)$ correctly as living things. Also, more than half of the participants classified two items: egg (71.54\%) and pupa (64.3\%) correctly and half of the participants classified corn seed $(50 \%)$ correctly. However, less than half of the participants were able to classify four of the items: grass, tomatoes fruit, mushroom and human bone correctly with percentage weighting of $48.6 \%$, $44.3 \%, 30 \%$ and $25.7 \%$ respectively.

The results further show that an appreciable number of the participants were undecided on how to classify items like corn seed (28.6\%), grass $(32.8 \%)$, tomatoes fruit (31.4\%) and mushroom $(42.9 \%)$. On the whole, at least $28 \%$ of the participants could not classify seven items as living things. Specifically, $18.6 \%$ could not classify egg as a living thing and $62.8 \%$ could not classify human bone as a living thing.
The classification of the items also included ten nonliving things. The results on how participants classified items in this category are presented in Table 2. The results from Table 2 show that among the non-living things category, all participants $100 \%$ (70) were able to correctly classify two items: spoon and stone. More than $50 \%$ of the participants classified four other items: mountain (92.9\%), clock (71.4\%), fossil (62.9\%) and fire (57.1\%) correctly and less than half of the participant could classify four items; wind $(47.1 \%)$, sun $(45.7 \%)$, river $(42.9 \%)$ and lightening (42.9\%).

The results further show that an appreciable number of participants were undecided about the classification of fire (22.9\%) and lightening (37.2\%). In summary, for the non-living things, at least $6 \%$ of the participants could not classify eight items as non-living. Specifically, $7.1 \%$ could not classify mountain as a non-living thing and $37.1 \%$ could not classify lightening as a non-living thing.

Table 2: Frequency Distribution of Participants Responses on Classification of Non-living Things

\begin{tabular}{lllllllll}
\hline \multicolumn{1}{c}{ Items } & \multicolumn{3}{c}{ Correct Answer } & \multicolumn{3}{c}{ Incorrect Answer } & Undecided & \multicolumn{2}{c}{ Total Responses } \\
& No. & $\%$ & No. & $\%$ & No. & $\%$ & No. & $\%$ \\
Spoon & 70 & 100 & 0 & 0 & 0 & 0 & 70 & 100 \\
Stone & 70 & 100 & 0 & 0 & 0 & 0 & 70 & 100 \\
Mountain & 65 & 92.9 & 0 & 0 & 5 & 7.1 & 70 & 100 \\
Clock & 50 & 71.4 & 10 & 14.3 & 10 & 14.3 & 70 & 100 \\
Fossil & 44 & 62.9 & 14 & 20 & 12 & 17.1 & 70 & 100 \\
Fire & 40 & 57.1 & 14 & 20 & 16 & 22.9 & 70 & 100 \\
Wind & 33 & 47.1 & 26 & 37.2 & 11 & 15.7 & 70 & 100 \\
Sun & 32 & 45.7 & 35 & 50 & 3 & 4.3 & 70 & 100 \\
River & 30 & 42.9 & 29 & 41.4 & 11 & 15.7 & 70 & 100 \\
Lightening & 30 & 42.9 & 14 & 20 & 26 & 37.1 & 70 & 100 \\
\hline
\end{tabular}

\section{Analysis of Qualitative Data}

This part dealt with reasons for classifying items as living or non-living things through interview. An interview was conducted to find out the reasons participants (respondents) had for classifying the living and non-living things. Seven themes; movement, respiration, feeding, excretion, growth, sensitivity and reproduction, which are attributes of living things, were generated as correct reasons (conception) given by participants for classifying the ten items under the living things category. Out of the seven themes, feeding, respiration and reproduction were the most mentioned by all participants and movement, excretion, and sensitivity respectively, were the least mentioned.
Again, participants who wrongly classified living things as non-living gave incorrect reasons (intuitive conception) for their classifications. For this category of participants, reasons given were associated with the lack of movement, growth, excretion or sensitivity of the living items such as human bone, egg, pupa, corn seed, tomato fruit and mushroom. For instance, one participant said that a bird's egg could not move and grow so it is a non-living thing. Another participant indicated that the pupa is not a living thing because it cannot grow. Yet another participant commented that the mushroom does not grow, it is not sensitive to touch and it does not move. The following excerpts were among those extracted from the interview: 
Researcher: Why did you classify these items under non-living things?

Respondent 4: The corn seed has no life in it because it is immobile. It just serves as food, so it is a nonliving thing.

Respondent 24: The human bone does not excrete and respire, so it is a non-living thing.

Respondent 69: We grow grass just to beautify the environment. It does not move so it has no life.

Respondent 12: Tomato fruit is non-living because it cannot move. It only serves as food.

During the interview session, majority of the participants gave reasons for classifying the ten nonliving items using their inability to exhibit the seven attributes associated with living things. Thus, the seven themes generated were lack of the following: movement, respiration, feeding, excretion, growth, sensitivity, and reproduction. Out of the seven themes, lack of growth and reproduction were the most mentioned by participants as reasons for classifying the non-living items. Surprisingly, no participant mentioned the lack of sensitivity and excretion as reason for classifying these non-living items.

Further, the analysis of the interview data also revealed that participants who wrongly classified some of the non-living items gave reasons associated with the movement and production of energy of such items. For instance, participants indicated that items such as the sun, wind, river, clock and fire exhibited an attribute of movement, thus, the reason for classifying them as living. In support of this, one participant said, "the sun is a living thing because it moves"[Respondent: 24]. Another participant said, "The wind is a living thing because it moves from one place to another" [Respondent: 12]. Again, another participant said: "the river flows and supports life, that is why it is a living thing"[Respondent: 15]. Furthermore, another participant reported: "the clock is a living thing because it can rotate on its own without anyone's help"[Respondent: 69]. Yet another participant commented: "fire is a living thing because it can spread from one place to another. It also produces heat or warmth, which supports life" [Respondent: 12].
A few participants gave reasons for the classification of the sun, fire, and thunder in attribution to the production of energy. In line with this finding, one participant said, "the sun is a living thing because it gives us energy and light" [Respondent: 4]. Another participant also said, "fire is a living thing because it provides us with heat" [Respondent: 69], and another participant indicated, "thunder is a living thing because it produces heat in the form of electric shock and light" [Respondent: 33].

\section{Discussion of Findings}

The study was conducted to find out Early Childhood pre-service teachers' conceptions of living and nonliving things. In the study, pre-service teachers were asked to classify twenty items as living or non-living, and provide reasons for their classification. The results showed that more than $72 \%$ and $93 \%$ of the participants could correctly classify most items as living and non-living things respectively, and were able to give correct reasons (conception) for their classification.

The results also revealed that among the attributes, the one most mentioned by participants as a reason for their classification was feeding. Participants saw the ability to feed as a major characteristic of a living thing. The least mentioned attribute was sensitivity. Therefore, it could be inferred from this finding that sensitivity was not an attribute that participants were familiar with. This study's revelation of feeding as the most mentioned attribute by students contradicts Ozgur's (2018) in which mobility was identified as the most mentioned attribute for classifying an item as living or non-living.

With regard to the results above, $74.3 \%, 71.4 \%$, $55.8 \%$ and $51.5 \%$ of the participants failed to correctly classify items such as human bone, mushroom, tomatoes fruit and grass respectively as living things because of the persistence of intuitive conceptions. With respect to the non-living things, $57.4 \%, 57.1 \%, 54.3 \%$ and $52.9 \%$ of the participants could not classify correctly lightening, river, sun and wind respectively due to their intuitive conceptions. Analyses of the reasons that participants gave for wrongly classifying human bone as non-living show that even though they knew that bones exist in the human body, they did not consider it as a living entity. This finding ties in with previous literature. In Ozgur's (2018) study, for instance, it was revealed that participants failed to classify the human teeth as living because they (participant) concluded that 
the teeth did not exhibit any of the attributes of living things. They considered animals and humans as complex; thus, some parts of them are erroneously classified as non-living.

Similarly, participants who had intuitive conceptions about living things used lack of mobility of such items as mushroom, corn, and grass and classified them as non-living things. To the contrary, they classified non-living items that exhibited evidence of motion such as the sun, moon and wind as living things. This finding agrees with Hatano et al. (1993) and Stavy and Wax's (1989) findings that because plants and fungi lacked autonomous motion, learners are quick to wrongly classify them as nonliving things. This finding also ties in with Stavy and Wax's (1989) assertion that learners have the tendency of classifying certain non-living objects, which seem to have motion, as living. Clearly, their understanding was influenced by how they perceived these concepts outside the classroom. These reasons, when properly scrutinized, were influenced by pre-service teachers' everyday conceptions (Davis, 2016). For example, a preservice teacher said: "fire is a living thing because it can spread from one place to another".

\section{Conclusions and Recommendations}

This section gives the conclusion and then comes up with recommendations of the study:

\section{Conclusions}

The majority of the pre-service teachers had the right conception about living and non-living things as they could correctly classify items and give appropriate justification for their classification. The study however concludes that some of the preservice teachers, although few, wrongly classified some of the items due to the intuitive conceptions they had about these items. Based on the findings of this study, it was concluded that although the concept of living and non-living things is taught from the primary school through the high school levels and beyond, intuitive conceptions about this topic still exists even among Early Childhood first year undergraduate pre-service teachers.

The study has revealed a knowledge gap in preservice teachers' conceptions of living and non-living things, a concept that is rudimentary in scientific literacy. This puts the pre-service teacher's professional prospects in a balance. The classification of living and non-living things is included in the Ghanaian Science curriculum taught at the early childhood level through the senior high school level and prospective early childhood teachers are expected to teach it when they begin their teaching career. If they are unable to classify living things after going through pre-tertiary education, where Science is a compulsory subject for all students, how can it be expected of them to teach it to early grade learners effectively? Similarly, pre-service teachers are likely to pass on this misconception to early graders if not revealed and corrected during initial teacher training.

Therefore, addressing situations of this kind should be the focus of Science Educators. This and other related basic Science concepts should be thoroughly and effectively taught to ground prospective teachers to positively impact early graders after initial teacher training. This knowledge gap, if not well addressed, could lead to a viscous cycle that will result in a situation where the nation will be bereft of learners capable of studying Science and Science related courses to the highest levels with global competitiveness.

\section{Recommendations}

Some educational implications that may arise from this study have to do with the cognitive challenge pre-service teachers go through when classifying items that are not in alignment with their intuitive conceptions. Science teachers at all levels of the educational system in Ghana should be made aware of these cognitive challenges so they become conscious about the nature of examples and handson-activities they use in illustrating scientific concepts and phenomena in their classrooms.

For this to be achieved, it is prudent for Science teachers to use research-backed strategies in teaching the concept of living and non-living things for pre-service teachers to have a robust understanding of living and non-living things and their characteristics. For instance the use of inductive rather than deductive approach to teach science concepts should be preferred, as the inductive approach engages learners in activities, which enable them to identify these characteristics from a myriad of examples. This contradicts the deductive approach, which is definitive, leaving learners to look for their own examples, a situation that usually leads to misconceptions. In this light, Science teachers should always try to use familiar examples, which correspond with learners' intuitive concepts first, before they use unfamiliar examples, 
in order to reduce the cognitive challenge that students may go through.

Finally, it is important for Science educators to interrogate pre-service teachers' incorrect responses to address underling misconceptions during lessons rather than deferring them and wishing they will self- correct in future. Evidence from literature does not suggest that self-correction is possible. In effect, Science teachers should treat scientific concepts comprehensively, systematically and in a manner that incorporates the intuitive conceptions and their modification into the desired scientific concepts necessary for acquiring scientific knowledge and for success in school and later life.

As mentioned earlier, this is a base-line study conducted in only one Ghanaian College of Education. Thus, the findings cannot be generalized for Early Childhood first-year pre-service teachers in all Ghanaian Colleges of Education. Therefore, it is important for a major study to be conducted using a larger sample size to determine the conception of living and non-living things among all first-year Early Childhood pre-service teachers in Ghana. Also, the use of qualitative data collection procedures in the future study need to be more rigorous to unearth underlying reasons for some of the justifications which participants gave for wrongly classifying some of the items. Further studies could also be conducted between first year pre-service teachers and final year pre-service teachers to find out the effect the undergraduate Early Childhood course has on pre-service teachers' intuitive conceptions on living and non-living things.

\section{Reference}

Babai, R., Sekal, R., \& Stavy, R. (2010). Persistence of the intuitive conception of living things in adolescence. Journal of Science Education Technol, 19, 20-26.

Bahar, M. (2003). Misconceptions in biology education and conceptual change strategies. Education Sciences Theory Practice, 3, 55-64.

Cohen, L., Manion, L., \& Morrison, L. (2006). Research methods in education ( $6^{\text {th }}$ ed.). Routedge: USA

Davis, E. K. (2016). Cultural influences on Ghanaian primary school pupils' conceptions in measurement and division of fractions.
African Journal of Educational Studies in Mathematics and Sciences 12, 1-15.

Dimec, D., S. \& Strgar, T. (2017). Scientific conceptions of photosynthesis among primary school pupils and student teachers of biology. Center for Educational policy studies Journal 7(1) 49-68. https://doi.org/10.26529/cepsj.14

Duitt, R. (2007). Students' and teachers' conceptions and science education: a bibliography. http://www.ipn.unikiel.de/aktuell/stcse/stcse.html

Fouquet, N., Megalakaki, O., \& Labrell, F. (2016). Children's understanding of animal, plant, and artifact properties between 3 and 6 years. In Child Development, 26, 20-32. https://doi.org/10.1002/icd.2032

Gallimore, R., \& Tharp, R. (1990). Teaching mind in society: Teaching, schooling and literate discourse. In: L. C. Moll (Ed.), Vygotsky and Education: Instructional implications and applications of socio-historical psychology (pp. 175-205). Cambridge: Cambridge University Press.

Gallegos-Ca'zares, L., Garci'a-Rivera, B., FloresCamacho, F., \& Caldero' n-Canales, E. (2016). Models of living and non-living beings among indigenous community children. Review of Science, Mathematics and ICT Education, 10(2), 5-27.

Hanson, R., \& Seheri-Jele, N. (2018). Assessing conceptual change instruction accompanied with concept maps and analogies: A case of acid-base strengths. Journal of Turkish Science Education, 15(4), 55-64.

Hatano, G., Siegler, R., Richards, D., Inagaki, K., Stavy, R., \& Wax, N. (1993). The development of biological knowledge: a multi-national study. Cogn Dev (8) 47-62.

Hellden, G. F., \& Solomon, J. (2004). The persistence of personal and social themes in context: Long and short-term studies of students' scientific ideas. https://doi.org/10.1002/sce.20003. 
Kurt, H. (2013). Biology student teachers' cognitive structure about "living thing". Educ. Res. Rev. 8(12), 871-880.

Labrell, F., \& Stefaniak, N. (2011). The development of diachronic thinking between 6 and 11 years. The case of growth and death. International Journal of Behavioral Development, 35(6), 532-541.

Laurendeau, M., \& Pinard, H. (1962). Causal thinking in the child. New York: International University Press.

Martínez-Losada, C., García-Barros, S., \& Garrido, M. (2014). How children characterize living beings and the activities in which they engage. Journal of Biology Education, 48(4), 201-210.

National Council for Curriculum and Assessment (2019). Science curriculum for primary schools (Basic 1 to 3). Ministry of Education, Ghana.

Noureddinea, Z., \& Zouhairea, L. (2017). Study of middle school students conceptions regarding the living concept. International Journal of Environmental \& Science Education, 12 (3), 475-484.

Opfer, J. E., \& Siegler, R. S. (2004). Revisiting preschoolers' living things concept: a microgenetic analysis of conceptual change in basic biology. Cognitive Psychology, 301-332. https://doi.org/10.1016/i.cogpsych.2004.0 1.002 .

Özgür, S. (2018). A study on young Turkish students' living things conception. Educational Research and Reviews, 13 (5), 150-165.
Piaget, J. (1929). The child's conception of the world. Oxford, UK: Harcourt Brace.

Pringle, M. R. (2006). Pre-service teachers' exploration of children's alternative conceptions: a cornerstone for planning to teach science. Journal of Science Teacher Education, 17, 291-307.

Rakison, D. H., \& Poulin-Dubois, D. (2001). Developmental origin of the animate-inanimate distinction. Psychological Bulletin, 127(2), 209-228. https://doi.org/10.1037/0033-2909.127.2.2 09.

Stavy, R., \& Wax, N. (1989). Children's conceptions of plants as living things. Human Development, 32, 88-94.

Tamir, P., Gal-Chappin, V. R., \& Nussnovitz, R. (1981). How do intermediate and junior high school students conceptualize living and nonliving? Journal of Research in Science Teaching, 18, 241-248.

Vygotsky, L. S. (1934/1987). Thinking and speech (N. Minick, Trans). In R. W. Rieber \& A.S. Carton (Eds.). The collected works of L. S. Vygotsky, 1, 37-288. New York: Plenum Press.

Yin, R. K. (2009). Case study research: Design and methods (4th Ed.). Thousand Oaks, CA: Sage. 